\title{
Laparoscopic ventral rectopexy for obstructed defecation syndrome
}

\author{
J. W. van den Esschert $\cdot$ A. A. W. van Geloven - N. Vermulst • \\ A. Groenedijk $\cdot$ L. Th. de Wit $\cdot$ M. F. Gerhards
}

Received: 14 June 2007 / Accepted: 18 October 2007/Published online: 5 March 2008

(C) The Author(s) 2008

\begin{abstract}
Introduction Obstructed defecation remains a serious syndrome. Several procedures have been applied to treat it. A concomitant enterocele excludes some of these procedures, because of potential threat of damaging the bowel. The aim of this study was to assess the outcome of patients who underwent laparoscopic nerve sparing ventral rectopexy for obstructed defecation syndrome with concomitant enterocele.

Methods Seventeen patients were included. Data about clinical history, physical examination and a defecogram were collected. All patients underwent a laparoscopic ventral rectopexy. Complications, hospital stay, postoperative morbidity and long-term outcome were documented. Results All patients underwent laparoscopic ventral rectopexy. The median operating time was 199 min (range 186-239 min). One conversion laparotomy was required. Six patients had postoperative complications (ileus $n=2$,
\end{abstract}

J. W. van den Esschert · A. A. W. van Geloven ( $\square)$

Department of Surgery, Tergooi Ziekenhuizen,

Van Riebeeckweg 212, Hilversum 1213 XZ, The Netherlands

e-mail: avangeloven@tergooiziekenhuizen.nl

J. W. van den Esschert

e-mail: j.w.vandenesschert@amc.uva.nl

N. Vermulst

Department of Surgery, St. Franciscus Gasthuis, Rotterdam, The Netherlands

\footnotetext{
A. Groenedijk

Department of Gynaecology, Onze Lieve Vrouwe Gasthuis,

Amsterdam, The Netherlands

L. Th. de Wit · M. F. Gerhards

Department of Surgery, Onze Lieve Vrouwe Gasthuis,

Amsterdam, The Netherlands
}

posttraumatic leg dystrophy $n=1$, wound infection $n=1$, incisional hernia $n=2$ ). The median hospital stay was 6 days (range 3-24 days). Fifteen patients had improvement of their defecation problem, although six patients still had minor constipation symptoms. In one patient the mesh was rejected and finally removed.

Conclusion Obstructed defecation syndrome is a combined functional and mechanical problem. In selected patients, especially when an enterocele is present, laparoscopic ventral rectopexy is a feasible technique, with an acceptable number of complications.

Keywords Obstructed defecation syndrome . Laparoscopy $\cdot$ Rectopexy $\cdot$ Enterocele

Obstructed defecation (OD) is a collective noun describing the inability to evacuate contents from the rectum. The prevalence of obstructed defecation in the Western world is about $7 \%$ in the adult population, occurring more frequently in females. Difficulties with defecation often arise during the fourth and fifth decade of life [1].

The pathophysiology of OD is unknown, but is most likely a complex pelvic floor problem due to several functional (e.g. impossibility to relax, paradoxal contraction of the puborectal muscle) or mechanical (e.g. rectocele, enterocele, intussusception, or full-thickness prolapse) factors. Symptoms include a feeling of incomplete evacuation and rectal obstruction, passage of hard stools, rectal or vaginal digitation and excessive straining in the constipated patient (freq $<3$ times weekly) [2].

Most symptoms associated with difficult defecation can improve by increasing dietary fibre. When unsuccessful, biofeedback can be the next step. Biofeedback aims at 
training the pelvic floor muscles to relax, sensory training with a rectal balloon, behavioural relaxation and defecation of simulated stool [3]. Another therapeutic option is surgery. A lot of procedures have been described. The type and moment of surgery is still controversial and depends on the pathological substrate. Especially the existence of an enterocele excludes some (new) anal procedures [4]. Often in these cases a transabdominal procedure is inevitable. The decision of which kind of abdominal procedure would be preferable is not easy $[5,6]$. Several types of rectopexies have been described in literature: with or without resection and with or without the use of prosthetic material. Because of the fact that a resection would introduce an extra risk for anastomotic leakage and a mesh could be helpful in sealing the deep pelvic floor, we started to perform a ventral rectopexy with mesh and without resection. The procedure was suitable for laparoscopy and was performed using a nerve-sparing technique. The aim of this study was to assess the outcome of patients who underwent this procedure for obstructed defecation syndrome in combination with an enterocele. Because of the necessity for longer follow-up, we analysed the first group of consecutive patients who were operated with this technique, despite the fact of dealing with a learning curve.

\section{Methods}

Patients and methods

In this retrospective study we searched for patients who underwent laparoscopic ventral rectopexy for obstructed defecation syndrome in our hospital between January 2002 and January 2005. Clinical history was taken and physical examination included anal sphincter function, pelvic floor descent, rectocele, enterocele, intussusception, mucosal prolapse, rectal prolapse and prolapse of the urogenital tract. A defecogram was performed in all patients. Complications, postoperative morbidity and hospital stay were documented. Telephonic review was done 2-5 years after the operation was performed. Longo's obstructed defecation syndrome (ODS) score system was used to evaluate defecation problems pre- and postoperative. Seventeen patients, all women, underwent laparoscopic ventral rectopexy. The median age was 55 (range 34-70) years old. At time of admission, 16 patients complained of constipation, 3 patients suffered from faecal incontinence, and 5 from urine incontinence. Thirteen patients had previously undergone a hysterectomy and two patients were nullipara. At physical examination, 18 patients seemed to have a rectocele and 14 an enterocele. A vaginal top prolapse was seen in five patients and three patients had an episiotomy scar. One patient had a posterior colpocele and five patients had a
Table 1 Findings on defecogram

\begin{tabular}{lll}
\hline $\begin{array}{l}\text { Defecogram } \\
\text { Findings }\end{array}$ & & $n=$ \\
Rectal prolapse & & 1 \\
Rectocele & Grade 1 & 3 \\
& Grade 2 & 5 \\
Gnterocele & Grade 3 & 8 \\
& Grade 1 & 0 \\
& Grade 2 & 5 \\
Intussusception & Grade 3 & 10 \\
Cystocele & Grade 4 & 2 \\
& & 4 \\
& Grade 1 & 3 \\
Vaginal prolapse & Grade 2 & 0 \\
Descending perineum & Grade 3 & 2 \\
\hline & Grade 4 & 1 \\
& Grade 1 & 1 \\
& Grade 2 & 4
\end{tabular}

cystocele. Only one patient suffered from a full-thickness rectal prolapse. All patients underwent a defecogram. They all showed an enterocele and 16 had a combination with a rectocele (Table 1). The operation was performed by a colorectal surgeon or by a senior surgical resident under direct supervision, together with a gynaecologist.

Surgical technique

Laparoscopic ventral rectopexy was performed. Five trocars were used. First the rectosigmoid was stretched. Then the peritoneum was opened laterally at the right side, continuing caudo-ventral in a J-shape. In front, the rectovaginal septum was opened. The lateral stalks were kept intact. The promontory was searched and, with the nerves in sight, the mesorectal plane was partial prepared. The right hypogastric nerve was left immobilised. The mesh, which consisted of a strip of Goretex ${ }^{\circledR}$ or Prolene (Gynamesh $\AA$ ), was introduced and fixed to the deep ventral aspect of the rectum with six nonabsorbable sutures. The posterior vaginal fornix was sutured to the mesh and the mesh was fixed just beneath the sacral promontory with an endotacker (Ethicon $\left.{ }^{\circledR}\right)$. The rectum was controlled on leakage and the peritoneum was closed over the mesh.

\section{Results}

Laparoscopic ventral rectopexy

The median operating time was 199 min (range 186$239 \mathrm{~min}$ ). The operating time decreased slightly during the 
years. A conversion laparotomy was required in one case because of a rectum perforation. No further perioperative complications occurred. During early follow-up, two patients developed a postoperative ileus; one could be treated conservatively, the other was operated upon because of fixation of the small bowel to the mesh, which resulted in a perforation. One patient suffered from neurological complaints of one leg, probably because of nerve entrapment due to the leg holder. Another patient developed a wound infection that could be treated conservatively. The median hospital stay was 6 days (range 3-24 days). During late follow-up, two patients were operated upon because of an incisional hernia.

\section{Long-term outcome}

Two to five years after the laparoscopic ventral rectopexy (mean follow-up 38 months), a telephonic review was performed in 16 patients, using Longo's ODS score system (Table 2). One patient was lost to follow-up. The preoperative ODS score was based on the anamnesis written in the status. The ODS score varied preoperative from 0 to 17 (mean $3.5 \pm 1.2 \mathrm{SEM}$ ). Postoperatively the score varied from 0 to 24 (mean $6.19 \pm 1.6$ SEM). Based on a confidence interval of $95 \%$, the distribution of the pre- and postoperative scores does not differ significantly (Wilcoxon signed rank test, $p=0.091)$. In 12 patients the ODS score was higher postoperatively than preoperatively. Postoperatively, 15 patients had defaecation two or more times a week, although five patients complained of severe straining. Ten patients had a sensation of incomplete evacuation ( $\leq 1 \mathrm{x} /$ week $n=5 ; 2 \mathrm{x} /$ week $n=2 ;>2 \mathrm{x} /$ week $n=3$ ). Four patients felt perineal/rectal pain or discomfort. Another four patients experienced inconvenience during the daily activities. Laxatives were still used by seven and enemas by two patients. Digitation during defecation was necessary in 5 patients. None of the patients complained of faecal incontinence after operation. Stress urine incontinence was experienced in seven and urge urine incontinence in 1 of the 16 patients.

However, during follow-up most patients (14/16) were satisfied about the operation and 13 said they would undergo the operation again. Two patients were not satisfied. One patient (ODS score 17 preoperative and 24 postoperative) suffered from dystrophy of one leg. In the second patient (ODS score 8 preoperative and 15 postoperative), the mesh was rejected and finally removed.

\section{Discussion}

What we have learned from the literature in the 1960s and 1970 s, is that a surgical resection should never be undertaken lightly in chronic constipation. Furthermore, it is essential to differentiate between impaired colonic transit and pelvic floor dysfunction. When a patient seems to suffer from an isolated pelvic floor dysfunction resulting in obstructed defecation, it is still a therapeutic challenge to subdivide the underlying problem. As is pointed out clearly by D'Hoore in a review, different mechanisms can eventually lead to obstructed defecation: defective rectal filling sensation, functional outlet obstruction, mechanical outlet obstruction and finally the dissipation of force vector at straining [1]. For surgeons it is always a challenge to restore the anatomy and therefore the mechanical outlet obstruction, often resulting from a severe rectal

Table 2 Longo's ODS score system

\begin{tabular}{|c|c|c|c|c|c|c|c|c|c|c|c|c|}
\hline \multicolumn{13}{|c|}{ Longo's ODS score } \\
\hline \multirow[t]{9}{*}{$\begin{array}{l}\text { ODS-SCORE } \\
\quad(0-40)\end{array}$} & Defecation frequency & $\begin{array}{l}1-2 \text { def/ } \\
1-2 \text { days }\end{array}$ & 0 & $\begin{array}{l}2 \text { def/wk or } \\
3 \text { def or } \\
\text { attempts/day }\end{array}$ & & 1 & $\begin{array}{l}1 \mathrm{def} / \mathrm{wk} \text { or } \\
4 \mathrm{def} \text { or } \\
\text { attempts/day }\end{array}$ & 2 & \multicolumn{3}{|c|}{$\begin{array}{l}<1 \mathrm{def} / \mathrm{wk} \text { or } \\
>4 \mathrm{def} \text { or } \\
\text { attempts/day }\end{array}$} & \\
\hline & Straining: - Intensity & No, light & 0 & Moderate & & 1 & Intensive & & & & & \\
\hline & - Extension & Short time & & & & 1 & Prolonged & & & & & \\
\hline & $\begin{array}{c}\text { Sensation of } \\
\text { incomplete } \\
\text { evacuation }\end{array}$ & Never & 0 & $\leq 1 \mathrm{x} / \mathrm{wk}$ & & 1 & $2 \mathrm{x} / \mathrm{wk}$ & 2 & \multicolumn{3}{|l|}{$>2 x / w k$} & \\
\hline & $\begin{array}{l}\text { Recto/perineal } \\
\text { pain/discomfort }\end{array}$ & Never & 0 & $\leq 1 \mathrm{x} / \mathrm{wk}$ & & 1 & $2 \mathrm{x} / \mathrm{wk}$ & 2 & \multicolumn{2}{|l|}{$>2 \mathrm{x} / \mathrm{wk}$} & & . \\
\hline & $\begin{array}{l}\text { Activity reduction } \\
\text { per week }\end{array}$ & Never & 0 & $<25 \%$ of activity & & 1 & $\begin{array}{l}25-50 \% \text { of } \\
\text { activity }\end{array}$ & 4 & \multicolumn{3}{|c|}{$\begin{array}{l}>50 \% \\
\quad \text { of activity }\end{array}$} & \\
\hline & Laxatives & Never & 0 & $<25 \%$ of def & 1 & & $\begin{array}{l}25-50 \% \text { of } \\
\text { def }\end{array}$ & 3 & \multirow[t]{2}{*}{$\begin{array}{c}>50 \% \text { of } \\
\text { def }\end{array}$} & 5 & Always & 7 \\
\hline & Enemas & & 0 & & 1 & & & 3 & & 5 & & 7 \\
\hline & Digitation & & 0 & & 1 & & & 3 & & 5 & & 7 \\
\hline
\end{tabular}


intussusception, enterocele and/or rectocele, should be addressed by first choice. During the years, many surgical techniques have been proposed, depending on further concomitant signs and problems. In general, the procedures can be divided in two groups: the perineal approach and the abdominal approach. Perineal procedures include perineal sutures (Thiersch procedure), Delorme's procedure, Altemeier procedure, perineal rectopexy and more recently the stapled transanal rectum resection (STARR) procedure [4]. Abdominal options include the abdominal resection rectopexy (Frykman-Goldberg procedure) and abdominal posterior rectopexy (Ripstein or Wells procedure) and eventually the ventral rectopexy [7-9]. With the help of new available equipment, all these abdominal procedures can now be performed laparoscopically.

As we know from rectal prolapse surgery, the perineal procedures are mostly used to treat older patients with a lot of comorbidity, because it is less invasive. Unfortunately these procedures give recurrence rates in $25-30 \%$ of all cases and functional problems, both constipation and incontinence are commonly seen [10]. For rectoceles and/ or intussusception alone, resulting in obstructed defecation, a stapled transanal rectum resection (STARR) is a welldocumented and simple technique [11]. However, when there is a possible concomitant enterocele at rest, the STARR procedure is not a safe option because of the potential danger of incorporating the enterocele into the stapler. Therefore, Petersen et al. suggested a combination of the STARR and laparoscopy to perform transanal resection without the threat of intra-abdominal lesions [12].

Beside the fact that all techniques are widely used, it is striking that no single test proved to be definitive for the evaluation of pelvic floor dysfunction. As mentioned above, it is quite impossible to simplify the underlying problem by only evaluating the anatomical substrate. With the help of tests like the colonic transit time, defecogram, dynamic magnetic resonance imaging (MRI), volumetry, manometry, electromyogram (EMG) and more, it is still difficult to objectify the severity of complaints. We have tried to use Longo's ODS score system during analysis, to evaluate patients symptoms pre- and postoperative. In Longo's own experience the threshold for operation has to be above 7 . Surprisingly, the score deteriorated in 12 patients $(75 \%)$. The mean preoperative score of $3.5 \pm 1.2$ standard error on the mean (SEM) was lower than the postoperative score of $6.19 \pm 1.6$ SEM. Using the Wilcoxon signed rank test, we notice a trend of deterioration of the score postoperatively, but this trend is not significant ( $p=0.091$ ).

A postoperative defecogram was not performed standard and in this retrospective analysis, a quality-of-life questionnaire was not used. However, by far most patients $(88 \%)$ were satisfied with the procedure, which is difficult to explain. Faecal incontinence as well as vaginal top prolapse complaints disappeared, but constipation remained in most patients. Nevertheless, $81 \%$ of all patients would not refuse to undergo the operation again.

In the case of an isolated mechanical outlet obstruction, which can be the result of a second- or third-degree enterocele, treatment of this cele by abdominal pexy can be efficacy on pelvic pressure but not on obstructed defecation [13]. This is confirmed by findings in an earlier study by Orrom et al., in which they conclude that rectopexy, by posterior or combined anterior and posterior fixation, can result in a significant amelioration of symptoms of obstructed defecation during initial follow-up, but during the time many patients reported even worsening of complaints as reflected by an increase in tenesmus, stool frequency and incomplete emptying [14]. In our series of patients, we had the same clinical findings. During shortterm follow-up, all patients had improvement of their defecation problems and eventually were satisfied [15]. At that time, only five patients had still constipation problems. During definitive follow-up, only in the minority of these patients was a control defecogram performed. In all these cases the enterocele and rectocele were improved or even completely disappeared. However, mean stool frequency was two or more times per week, but one-third of the patients still complained about severe straining, pain, incomplete evacuation and digitation.

Even the use of the ventral rectopexy technique in this series, which is advocated for its parasympatic nerve-sparing procedure, did not result in the same long-term follow-up results as is reported by others, resulting in improvement of constipation in $71 \%$ during 4 years follow-up [9]. This latter technique is developed on the four goals: prevention of damaging the parasympatic nerves, treatment or prevention of the anterior rectocele and internal intussusception by dividing the rectovaginal septum down to the pelvic floor and by fixation of the stretched rectum as low as possible at the anterior side, treatment and prevention of a vaginal vault or uterine prolapse by closure of the space between rectum and vagina by suturing the vaginal vault to the mesh and further treatment or prevention of an enterocele by reefing the peritoneum overlying the area of reconstruction and the mesh. On the contrary, one can argue that beside the possible innervation damage, also kinking of the sigmoid above the stretched rectum, possible local inflammation due to the mesh and resulting in scar tissue and stenosis and finally the disappearance of the so-called physiological enterocele, which can be helpful in emptying the rectum and rectocele, can possibly result in worsening of complaints.

Clearly, this technique is useful in resolving a complete rectal prolapse, which was the case in just one patient in this series. Recently, results in a large series of patients with rectal prolapse were published. A recurrence rate of $3.6 \%$ was reported. Furthermore, with the excuse that 
functional outcome was beyond the scope of the article, they analysed a subgroup of 42 patients, and constipation resolved in 84\% [8]. A meta-analysis of the comparison of open versus laparoscopic abdominal rectopexy for fullthickness rectal prolapse showed equal results with regards to recurrence and morbidity and a favourable result for laparoscopy with regard to length of hospital stay [16].

Comparison of the postoperative results of our patients operated upon the indication of obstructed defecation with the literature is difficult because in most articles the (laparoscopic) technique is only used in patients with a rectal prolapse. In our study we operated 17 patients. One conversion laparotomy was required. This is comparable with the study of D'Hoore et al. [7, 9]. Their mean operating time was shorter than that found in this series (140 versus $199 \mathrm{~min}$ ). Their mean operating time even decreased after the first 20 patients to $115 \mathrm{~min}$ so there is obviously a learning curve. In our study the operation time is not only the cutting time, but contains the time from induction until the end of anaesthetic use. The mean hospital stay in our study was 6 days, which is also comparable with that reported in the literature.

\section{Conclusion}

Obstructed defecation is a complex and multifactorial problem. In this series, patients were operated for a presumed mechanical outlet obstruction, resulting from a severe rectal intussusception, enterocele and/or rectocele and not for a rectal prolapse. The use of the relative new, nerve-sparing, ventral rectopexy technique with a laparoscopic approach was feasible and complications were comparable with the available literature. However, in a minority of patients, severe complications were found. Because of the lack of good pre- and postoperative test and scoring systems, it is difficult to quantify the results on pelvic floor function and obstructed defecation. We think that, in selected cases, the use of laparoscopic ventral rectopexy is a feasible technique that results in significant patient satisfaction, beside the fact that some form of constipation remains.

Open Access This article is distributed under the terms of the Creative Commons Attribution Noncommercial License which permits any noncommercial use, distribution, and reproduction in any medium, provided the original author(s) and source are credited.

\section{References}

1. D'Hoore A, Penninckx F (2003) Obstructed defecation. Colorectal Dis 5(4):280-287

2. Khaikin M, Wexner SD (2006) Treatment strategies in obstructed defecation and fecal incontinence. World $\mathbf{J}$ Gastroenterol 12(20):3168-3173

3. Fleshman JW, Dreznik Z, Meyer K, Fry RD, Carney R, Kodner IJ (1992) Outpatient protocol for biofeedback therapy of pelvic floor outlet obstruction. Dis Colon Rectum 35(1):1-7

4. Boccasanta P, Venturi M, Salamina G, Cesana BM, Bernasconi F, Roviaro G (2004) New trends in the surgical treatment of outlet obstruction: clinical and functional results of two novel transanal stapled techniques from a randomised controlled trial. Int J Colorectal Dis 19(4):359-369

5. Marchal F, Bresler L, Ayav A, Zarnegar R, Brunaud L, Duchamp $C$ et al (2005) Long-term results of Delorme's procedure and OrrLoygue rectopexy to treat complete rectal prolapse. Dis Colon Rectum 48(9):1785-1790

6. Mannaerts GH, Ruseler CH (2006) Surgical treatment of rectal prolapse. Ned Tijdschr Geneeskd 150(14):781-787

7. D'Hoore A, Cadoni R, Penninckx F (2004) Long-term outcome of laparoscopic ventral rectopexy for total rectal prolapse. Br J Surg 91(11):1500-1505

8. D'Hoore A, Penninckx F (2006) Laparoscopic ventral recto(colpo)pexy for rectal prolapse: surgical technique and outcome for 109 patients. Surg Endosc 2006 Oct 9

9. Silvis R, Gooszen HG, van EA, de Kruif AT, Janssen LW (1999) Abdominal rectovaginopexy: modified technique to treat constipation. Dis Colon Rectum 42(1):82-88

10. Lindsey I, Cunningham C (2004) Surgical treatment of rectal prolapse. Br J Surg 91(11):1389

11. Corman ML, Carriero A, Hager T, Herold A, Jayne DG, Lehur PA et al (2006) Consensus conference on the stapled transanal rectal resection (STARR) for disordered defaecation. Colorectal Dis 8(2):98-101

12. Petersen S, Hellmich G, Schuster A, Lehmann D, Albert W, Ludwig K (2006) Stapled transanal rectal resection under laparoscopic surveillance for rectocele and concomitant enterocele. Dis Colon Rectum 49(5):685-689

13. Jean F, Tanneau Y, Le Blanc-Louvry I, Leroi AM, Denis P, Michot F (2002) Treatment of enterocele by abdominal colporectosacropexy-efficacy on pelvic pressure. Colorectal Dis 2002;4(5):321-325

14. Orrom WJ, Bartolo DC, Miller R, Mortensen NJ, Roe AM (1991) Rectopexy is an ineffective treatment for obstructed defecation. Dis Colon Rectum 34(1):41-46

15. van Geloven AA, Groenedijk A (2006) Laparoscopic ventral rectopexy for obstructed defecation syndrome. Surg Endosc S139:258

16. Purkayastha S, Tekkis $\mathrm{P}$, Athanasiou T, Aziz O, Paraskevas $\mathrm{P}$, Ziprin P et al (2005) A comparison of open vs. laparoscopic abdominal rectopexy for full-thickness rectal prolapse: a metaanalysis. Dis Colon Rectum 48(10):1930-1940 